\title{
Recruitment of host functions suggests a repair pathway for late steps in group II intron retrohoming
}

\author{
Dorie Smith, ${ }^{1,3}$ Jin Zhong, ${ }^{2,3,4}$ Manabu Matsuura, ${ }^{2}$ Alan M. Lambowitz, ${ }^{2}$ and Marlene Belfort ${ }^{1,5}$ \\ ${ }^{1}$ Molecular Genetics Program, Wadsworth Center, New York State Department of Health and School of Public Health, State \\ University of New York at Albany, Albany, New York 12201, USA; ${ }^{2}$ Institute for Cellular and Molecular Biology, \\ Department of Chemistry and Biochemistry and Section of Molecular Genetics and Microbiology, School of Biological \\ Sciences, University of Texas at Austin, Austin, Texas 78712, USA
}

Retrohoming of group II introns occurs by a mechanism in which the intron RNA reverse splices directly into one strand of a DNA target site and is then reverse transcribed by the associated intron-encoded protein. Host repair enzymes are predicted to complete this process. Here, we screened a battery of Escherichia coli mutants defective in host functions that are potentially involved in retrohoming of the Lactococcus lactis L1.LtrB intron. We found strong (greater than threefold) effects for several enzymes, including nucleases directed against RNA and DNA, replicative and repair polymerases, and DNA ligase. A model including the presumptive roles of these enzymes in resection of DNA, degradation of the intron RNA template, traversion of RNA-DNA junctions, and second-strand DNA synthesis is described. The completion of retrohoming is viewed as a DNA repair process, with features that may be shared by other non-LTR retroelements.

[Keywords: Retroelement; retrotransposon; RNase H; Pol I; Pol III; repair polymerases]

Supplemental material is available at http://www.genesdev.org

Received June 14, 2005; revised version accepted August 15, 2005.

Movement of group II introns to allelic sites on DNA occurs via an RNA intermediate in a process termed retrohoming (for review, see Belfort et al. 2002; Lambowitz and Zimmerly 2004). Retrohoming pathways have been studied in detail for two related yeast mitochondrial introns (aI1 and aI2) and two bacterial introns (L1.LtrB and RmInt1) (Belfort et al. 2002; Lambowitz and Zimmerly 2004; Martinez-Abarca et al. 2004). The Ll.LtrB intron, which derives from Lactococcus lactis (Mills et al. 1996; Shearman et al. 1996), was shown to be functional in both splicing and retrohoming in Escherichia coli (Mills et al. 1997; Cousineau et al. 1998). In all organisms, the retrohoming of group II introns occurs by a process in which the excised intron RNA reverse splices into one strand of a DNA target site and is then reverse transcribed by the intron-encoded protein (IEP). This process is mediated by a ribonucleoprotein (RNP) particle that is formed during RNA splicing and contains the IEP and the excised intron lariat RNA. In addition to catalyti-

\footnotetext{
${ }^{3}$ These authors contributed equally to this work.

${ }^{4}$ Present address: The Scripps Research Institute, Department of Molecular and Experimental Medicine, SBR-10, 10550 North Torrey Pines Road, La Jolla, CA 92037, USA.

${ }^{5}$ Corresponding author.

E-MAIL belfort@wadsworth.org; FAX (518) 474-3181.

Article and publication are at http://www.genesdev.org/cgi/doi/10.1101/ gad. 1345105
}

cally active intron RNA, retrohoming of the Ll.LtrB intron is dependent upon three activities of the IEP (Belfort et al. 2002; Lambowitz and Zimmerly 2004; Lambowitz et al. 2005). These are RNA maturase, to stabilize the catalytically active structure of the intron RNA for RNA splicing and reverse splicing, DNA endonuclease, for cleavage of the target DNA to generate a primer for reverse transcription, and reverse transcriptase $(\mathrm{RT})$ for making a cDNA copy of the intron RNA (Fig. 1).

Completion of the retrohoming pathway in bacteria is distinguished from the major pathway in yeast by its independence of homologous recombination between donor and recipient (Eskes et al. 1997; Mills et al. 1997; Cousineau et al. 1998; Martínez-Abarca and Toro 2000). After complete reverse splicing of the Ll.LtrB intron and endonucleolytic cleavage of the second strand, 9 nucleotides (nt) downstream of the intron-insertion site, fulllength cDNA synthesis ensues in a process termed target DNA-primed reverse transcription (TPRT) (Fig. 1, steps 1-3). The later stages of retrohoming require degradation or displacement of the RNA strand, second-strand DNA synthesis, and possibly trimming of DNA ends, and ligation of junctions (Fig. 1, steps 4-7). However, the nature of these steps, and the enzymes involved, have not been defined for any group II intron.

Non-LTR-retrotransposons, which are evolutionarily related to mobile group II introns, also utilize a TPRT 
Smith et al.

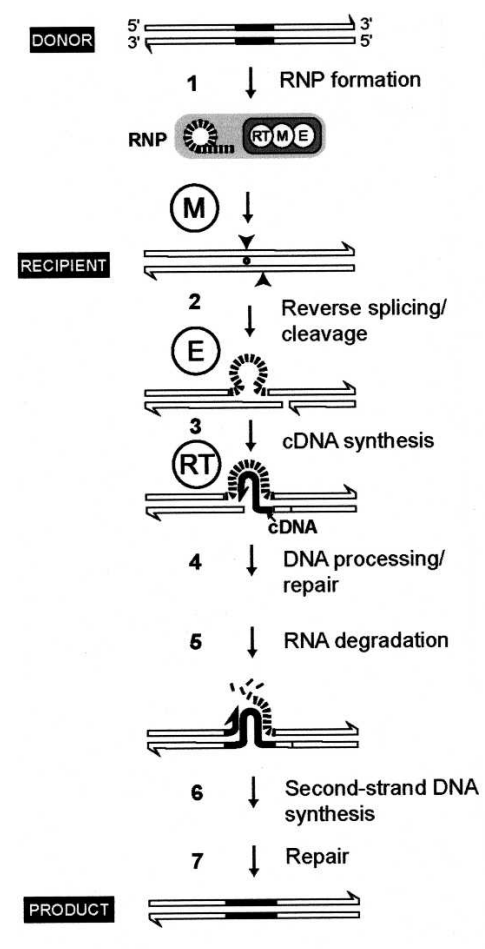

EXONDNA $\quad$ INTRON DNA IIIIIIIII INTRONRNA

Figure 1. Retrohoming pathway for the Ll.LtrB intron in $L$. lactis and E. coli. The steps in the pathway are as follows: (1) Transcription from the donor template, splicing, translation and RNP formation. The RNP consists of the intron lariat and IEP having RT, maturase (M), and DNA endonuclease (E) activities. (2) Cleavage of recipient DNA by reverse splicing into the top strand and endonuclease cleavage of the bottom strand, at the sites marked $\boldsymbol{\nabla}$ and $\boldsymbol{\Lambda}$, respectively. (3) cDNA synthesis. (4-7) Extended cDNA synthesis, RNA degradation, secondstrand DNA synthesis, and repair. The order of steps $4-7$ is unknown.

mechanism (Luan et al. 1993; Moran and Gilbert 2002). The protein encoded by the non-LTR-retrotransposons cleaves a DNA target site and then uses the cleaved 3' end as primer to synthesize a full-length cDNA of the element's RNA (Eickbush 2002). Here too, the mechanism of late steps in retrotransposition, including second-strand synthesis and the sealing of gaps, has remained obscure.

To investigate the nature of the late steps in retrohoming, we probed the role of host accessory functions. The retrohoming pathway has been studied in both L. lactis and E. coli and has been found to be mechanistically similar (Cousineau et al. 1998). Reliance on the IEP, as well as the distinctive independence of homology between donor and recipient, and the absence of coconversion tracks, are all identical. Furthermore, in both systems retrohoming is independent of RecA function. For these reasons, and because of the general availability of DNA and RNA processing mutants in E. coli, we selected this host in which to examine the potential involvement of cellular factors in retrohoming. We thereby demonstrate how a retrotransposon parasitizes its host through exploitation of cellular nucleolytic, polymerization, and repair activities, to promote its own spread.

\section{Results}

Assays for group II intron homing in E. coli

The plasmid-based assay described by Cousineau et al. (1998) was used to test the role of host accessory functions in retrohoming (Fig. 2A). In this assay, the group II intron donor plasmid contains drug-resistance marker PM1, and the intron contains an additional drug-resistance marker (IM), along with the group I $t d$ intron (I) in domain IV. The loss of the $t d$ intron by self-splicing reports the minimum number of homing events that have passed through an RNA intermediate. The compatible recipient plasmid contains the Ll.LtrB homing site (E1E2) and a different drug-resistance marker (PM2). After induction of Ll.LtrB expression, plasmids are extracted and digested with restriction enzymes to destroy the donor plasmid, then retransformed into E. coli. Then, homing products are selected for the IM and recipient PM2 markers, and screened for sensitivity to the donor PM1. Homing frequencies in the $0.1 \%-0.6 \%$ range (Fig. 2B, crosses 1 and 2) could be increased to $\geq 14 \%$ with expression of the ItrA gene downstream of exon 2 to generate a smaller intron (Fig. 2B, cross 3). The enhanced mobility frequency is thought to be due to decreased susceptibility of the smaller intron RNA to degradation by host nucleases (Guo et al. 2000).

A second assay, developed by Guo et al. (2000), was also used to check mutants with the most dramatic phenotypes (see Supplementary Tables S1-S3). In most cases, there was good agreement on host effects between the two assays, and where not, the disparities can be readily explained by the differences in assay conditions. A comparison between the two assays and related explanations are given in the Supplemental Material, where the assay described in the text is referred to as assay A, and the second assay as assay $\mathrm{B}$.

To ensure that neither replication of the donor or recipient plasmids nor intron expression was compromised in each of the different hosts, we performed a gel assay on donor and recipient plasmid levels before and after induction of Ll.LtrB, as described (Cousineau et al. 1998). Conversion of the recipient plasmid to homing product and/or its disappearance due to cleavage by the RNP, with subsequent plasmid degradation by host nucleases, were interpreted as satisfactory expression. Additionally, LtrA expression was confirmed in many cases on protein gels. If either or both the replication and expression criteria were not satisfied, the result of the retrohoming assay was discarded. Loss of the $t d$ intron was also monitored to ensure that homing events had passed through an RNA intermediate. 


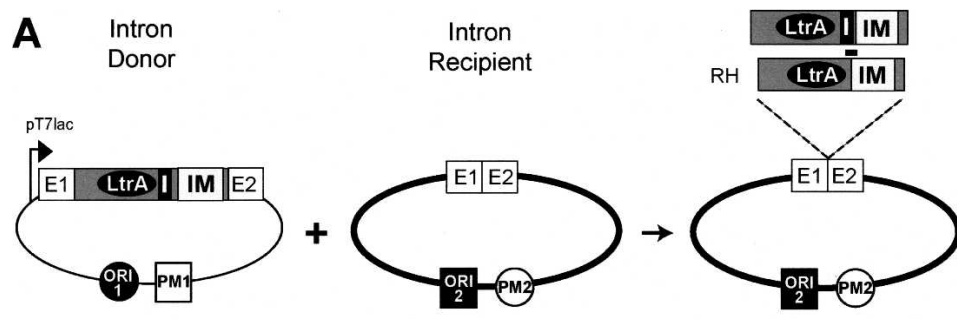

Homing Product

\section{B}

\begin{tabular}{|c|c|c|c|c|c|c|c|c|c|c|c|}
\hline \multirow[b]{2}{*}{$\begin{array}{c}\text { Cross } \\
\# \\
\end{array}$} & \multicolumn{5}{|c|}{ Intron Donor } & \multicolumn{3}{|c|}{ Intron Recipient } & \multicolumn{2}{|c|}{ Homing Product (HP) } & \multirow[t]{2}{*}{ Use of cross } \\
\hline & Name & IM & PM1 & Ori1 & Length & Name & PM2 & Ori2 & Selection & Efficiency \% & \\
\hline 1 & pLI1td ${ }^{+} K R^{\prime}$ & Kan & Amp & ColE1 & 3989 & pLHS1 & $\begin{array}{l}\text { Cam } \\
\text { Tet } \\
\mathrm{Spc}\end{array}$ & PA15 & $\begin{array}{l}\text { Kan-Cam } \\
\text { Kan-Tet } \\
\text { Kan-Spc }\end{array}$ & $0.1-0.6$ & General \\
\hline 2 & pSCLtrAtd $d^{+}$KR' & Kan & Amp & pSC101 & 3989 & pR1A-HS & Spc & Bhr & Kan-Spc & 0.1 & For Pol I mutant \\
\hline 3 & pACD3-TpR8 & Тгр & Cam & PA15 & 1250 & $\begin{array}{l}\text { pBRR3- } \\
\text { ItrB }\end{array}$ & Amp & ColE1 & Trp-Amp & $14-15$ & For Pol III mutant \\
\hline
\end{tabular}

Figure 2. Homing assay. (A) Schematic of assay. Plasmids are described in $B$ and Supplemental Material. (IM) Intron marker; (PM1) donor plasmid marker; (PM2) recipient plasmid marker. ORI1 and ORI2 are compatible origins of replication. Homing products were selected for the IM and PM2. The pT7lac designation indicates that the T7 polymerase, which drives intron expression, is under control of a lac promoter. White rectangles are exons (E1 and E2), and dark-gray rectangles represent the group II intron. The black rectangle with a white I represents the group I $t d$ intron used to monitor retrohoming. Two homing products are shown, with the lower $(\mathrm{RH})$ representing the verified retrohoming product lacking the group I intron. These products were detected by hybridization to a splice junction probe (short black bar). (B) Characteristics of intron donor, recipient, and homing products in different crosses. Plasmid donors and recipients are described in Materials and Methods and Supplemental Material. (IM) Intron marker, with resistance to kanamycin (Kan) and trimethoprim (Trp). (PM1) Donor plasmid marker with resistance to ampicillin (Amp) and chloramphenicol (Cam). (ORI1) Replication origin of donor plasmid. Intron length (nucleotides) depends on whether LtrA is expressed from within or outside of the intron. (PM2) Recipient plasmid marker with drug resistances as above, as well as tetracycline (Tet) and spectinomycin (Spc). (ORI2) Replication origin of recipient plasmid. Selection was for IM-PM2. Efficiency $=($ homing product $) /$ recipient $\times 100$.

\section{Dependence of retrohoming efficiency on DNA-processing functions}

Table 1 lists the host mutants tested for DNA-processing activities, along with a brief description of the function of the mutated protein. The mutants were screened with cross 1 , and those that showed a greater than threefold difference in homing frequency were considered to have a facilitatory or inhibitory effect on retrohoming. For each mutant, homing efficiency is expressed as the value relative to that in an isogenic parental host (Supplementary Table S4).

First, we tested a series of mutants deficient in exonuclease, helicase, or DNA repair functions. There were minimal effects (less than twofold) in most cases, including with the nuclease SbcB, RecB, SbcC, RecD, and RecF mutants, and with helicase RecG, RuvB, UvrD, RecQ, and Rep mutants. However, RecJ, MutD, and SbcD mutants, with reduced $5^{\prime}-3^{\prime}, 3^{\prime}-5^{\prime}$ and ATP-dependent exonuclease activities, respectively, were four- to fivefold depressed in retrohoming, and a temperature-sensitive (ts) ligase mutant (lig-ts7) was fourfold depressed at the restrictive temperature of $37^{\circ} \mathrm{C}$. A mutation in $x t h A$, which encodes a $3^{\prime}-5^{\prime}$ exonuclease, gave a greater than eightfold increase in retrohoming frequency. The phenotypes of these mutants will be rationalized in the Discussion in the context of a model for the late stages of retrohoming.

\section{Relationship of retrohoming efficiency to RNA-processing functions}

Several general RNA-processing mutants were also screened for their ability to support retrohoming (Table
2). Although StpA, which promotes RNA annealing and strand exchange, appears not to affect retrohoming, RNase I and RNase E, degradative enzymes, do. Retrohoming was enhanced by greater than fourfold in the RNase I mutant, and elevated $\sim 10$-fold in a ts RNase E mutant. These increases likely reflect the fact that RNases I and E contribute to degradation of the intron RNA.

The expectation is that retrohoming requires enzymes to degrade the intron RNA template after reverse transcription. Two main candidates in $E$. coli for degrading RNA in RNA/DNA duplexes are RNase $\mathrm{H}$ and the $5^{\prime}-3^{\prime}$ exonuclease activity of $E$. coli DNA polymerase I (Pol I), which degrades RNA primers in DNA replication. First, RNase $\mathrm{H}$ mutants were examined. The exact functions of RNase $\mathrm{H} 1$ and $\mathrm{H} 2$ in cellular processes are obscure, and while single and double mutants are both viable, RNase H1 plays the dominant role (Nicholson 1999). Mutation of RNase H1 ( $r n h A)$ caused a $>30$-fold drop in homing efficiency. In contrast, mutation of RNase $\mathrm{H} 2$ $(r n h B)$ had only a twofold effect, while the RNase H1/H2 double mutant was again $>30$-fold depressed. Accordingly, this effect could be reversed by complementation with the $r n h A$ but not the $r n h B$ gene expressed from a compatible plasmid (Table 2, see footnote d). These results suggest that RNase $\mathrm{H}$ contributes to degradation of the intron RNA template, with RNase $\mathrm{H} 1$ playing the dominant role.

Pol I, the product of the polA gene, is a multifunctional protein that catalyzes lagging-strand DNA synthesis. Its $5^{\prime}-3^{\prime}$ exonuclease activity, which is involved in removing RNA primers from Okazaki fragments (Kornberg and Baker 1992), might be involved in intron RNA degradation before second-strand DNA synthesis. For 
Smith et al.

Table 1. Homing of the Ll.LtrB intron in mutants defective in DNA processing functions

\begin{tabular}{|c|c|c|}
\hline Mutant (mutation) ${ }^{\mathrm{a}}$ & Function & Homing efficiency ${ }^{\mathrm{b}}$ \\
\hline \multicolumn{3}{|l|}{ DNA Exonucleases } \\
\hline $\operatorname{RecJ}(\Delta r e c J)$ & $5^{\prime}-3^{\prime} \mathrm{ss}^{\mathrm{c}}$ & $0.18 \pm 0.05$ \\
\hline $\mathrm{SbcB}(s b c B 15)$ & $3^{\prime}-5^{\prime}$ ss & $2.58 \pm 0.89$ \\
\hline $\operatorname{RecB}(\operatorname{rec} B 21)$ & $5^{\prime}-3^{\prime}$ ss, $3^{\prime}-5^{\prime}$ ss & $2.19 \pm 0.56$ \\
\hline MutD (mutD5) & $3^{\prime}-5^{\prime} d s^{c}$ and ss & $0.27 \pm 0.17$ \\
\hline XthA $(x \operatorname{thA} 1)$ & $3^{\prime}-5^{\prime} \mathrm{ds}$ & $8.63 \pm 2.69$ \\
\hline $\operatorname{SbcC}(s b c C 201) \quad\rangle$ & ATP dependent exo suppressors of recB+C & $0.51 \pm 0.17$ \\
\hline SbcD (sbcD300::kan) & & $0.28 \pm 0.14$ \\
\hline $\operatorname{RecD}(r e c D 1014)$ & $5^{\prime}-3^{\prime}$ ss, $3^{\prime}-5^{\prime}$ ss & $0.92 \pm 0.31$ \\
\hline $\operatorname{RecF}($ recF143) & $5^{\prime}-3^{\prime} \mathrm{ds}$ & $0.69 \pm 0.16$ \\
\hline \multicolumn{3}{|l|}{ DNA Helicases } \\
\hline RecG (recG258 Tn10::kan) & $3^{\prime}-5^{\prime}$ helicase & $1.08 \pm 0.34$ \\
\hline RuvB (ruvB9) & $5^{\prime}-3^{\prime} \mathrm{jxn}^{\mathrm{c}}$ helicase RNA/DNA hybrids & $1.46 \pm 0.28$ \\
\hline UvrD (uvrDs291::tet) & 3'-5' RNA/DNA hybrids & $1.17 \pm 0.31$ \\
\hline $\operatorname{RecQ}(\operatorname{rec} Q 1)$ & 3'-5' DNA helicase & $0.70 \pm 0.13$ \\
\hline Rep (srep::kan) & $3^{\prime}-5^{\prime}$ RNA/DNA hybrids & $1.61 \pm 1.0$ \\
\hline \multicolumn{3}{|l|}{ DNA repair Functions } \\
\hline Lig (Iig7 [ts]) & Ligase mutant $\left[37^{\circ} \mathrm{C}\right]$ & $0.26 \pm 0.08$ \\
\hline
\end{tabular}

${ }^{a}$ Full genotype of parental strains and sources of mutants are listed in Supplementary Table S4.

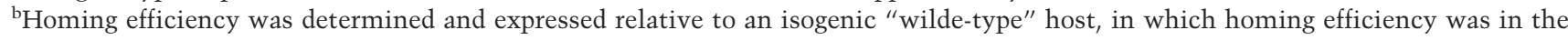
range indicated in Figure 2B. Numbers reflect the mean \pm standard error for at least three independent experiments. The percentage of homing products that had lost the group I intron was also determined for each cross, verifying the retrohoming pathway. Loss of the $t d$ intron occurred in $22 \%-75 \%$ of the homing products (see Supplemental Material), reflecting the lower limit of mobility via an RNA intermediate. It is uncertain whether this range reflects differences in retrohoming, or slightly altered splicing efficiencies of the group I intron in the mutant hosts.

c/ss) Single-stranded; (ds) double-stranded; (jxn) junction.

testing Pol I mutants, a new donor and recipient pair with Bhr and pSC101 replication origins was constructed, because neither p15A nor ColE1 replicons can be maintained in polA hosts (Fig. 2B, cross 2). The polA107 mutant, which contains a point mutation that inhibits $5^{\prime}-3^{\prime}$ exonuclease activity, resulted in a fourfold reduction in retrohoming, whereas deletion of this domain in the $\Delta$ polA :: $/ \mathrm{F}^{\prime}$ klenow strain, eliminated mobility below detectable levels. Notably, RNase H1 overexpressed from a plasmid was unable to complement the
Pol I-5'-3' exo deletion mutant (data not shown). Thus, as expected from their biochemical activities, RNase H1 and Pol I-5'-3' exo likely act at different steps in RNA degradation.

The LtrA protein has minimal DNA-dependent DNA polymerase activity in vitro

We next wished to identify the DNA polymerase that conducts second-strand cDNA synthesis. To test

Table 2. Homing of the Ll.LtrB intron in mutants defective in RNA processing functions

\begin{tabular}{|c|c|c|}
\hline Mutant (mutation)/Plasmid ${ }^{\mathrm{a}}$ & Function & Homing efficiency $^{\mathrm{b}}$ \\
\hline \multicolumn{3}{|l|}{ General } \\
\hline RNase I (rna-19) & RNA degradation & $4.19 \pm 2.09$ \\
\hline RNase E (rne-1) ts & RNA processing and decay $\left[44^{\circ} \mathrm{C}\right]$ & $11.68 \pm 4.09$ \\
\hline $\operatorname{StpA}^{\mathrm{c}}(\Delta \operatorname{stp} A:: t e t)$ & RNA annealing & $0.58 \pm 0.11$ \\
\hline H-NS $(\Delta h n s:: c a t)$ & Regulator + nucleoid protein & $1.06 \pm 0.3$ \\
\hline \multicolumn{3}{|l|}{ Intron degradation } \\
\hline RNase H1 (rnhA339::cat) & & $0.03 \pm 0.01$ \\
\hline RNase H2 (rnhB716::kan) & Degrade RNA from RNA/DNA hybrids & $0.49 \pm 0.16$ \\
\hline $\mathrm{RNase} \mathrm{H} 1+\mathrm{H} 2(r n h A, r n h B) /$ & & $0.03 \pm 0.02$ \\
\hline RNase $\mathrm{H} 1 / \mathrm{pLHS}^{\mathrm{d}}$ & Complementation $^{\mathrm{d}}$ & $0.05 \pm 0.01$ \\
\hline RNase H1/pLHS1-rnhA & Complementation $^{\mathrm{d}}$ & $0.48 \pm 0.18$ \\
\hline RNase H1/pLHS1-rnhB & Complementation $^{\mathrm{d}}$ & $0.06 \pm 0.02$ \\
\hline
\end{tabular}

${ }^{\mathrm{a}, \mathrm{b}}$ As footnotes a and $\mathrm{b}$ of Table 1 .

${ }^{\mathrm{c}}$ Although StpA action on RNA is more potent than that of its paralog H-NS, H-NS does have some RNA-binding capability (Cusick and Belfort 1998; Brescia et al. 2004) and was therefore included in this table.

${ }^{\mathrm{d}}$ The $r n h A$ mutant was transformed with the recipient plasmid pLHS1 (Fig. 2A,B), either with or without the $r n h A$ and $r n h B$ genes. 
whether LtrA itself might play a role, we performed in vitro assays using the template-primer substrates shown in Figure 3 (I-IV). These assays used two substrates to test for DNA-dependent DNA polymerase activity: annealed synthetic DNA oligonucleotides that mimic a potential substrate for second-strand DNA synthesis in which the $3^{\prime}$ end of E1 is used as a primer for top-strand synthesis (substrate I) and the artificial template/primer substrate poly (dA)/oligo(dT) ${ }_{18}$ (substrate II). As controls to assay RT activity, we used a previously described natural substrate mimic denoted Ll.LtrB/E2+10 (substrate III) and the artificial template/primer substrate poly $(\mathrm{rA}) /$ oligo $(\mathrm{dT})_{18}$ (substrate IV). The former consists of Ll.LtrB RNA (an in vitro transcript containing the Ll.LtrB- $\triangle$ ORF intron and flanking exons) with an annealed DNA primer $(\mathrm{E} 2+10)$, whose 3' end corresponds to that of the cleaved bottom strand normally used as the primer for reverse transcription (Matsuura et al. 1997; Wank et al. 1999).

LtrA displayed high activities in both the bottomstrand RT and poly(rA)/oligo(dT) assays (Fig. 3, assays 5-7). However, no significant DNA-dependent DNA
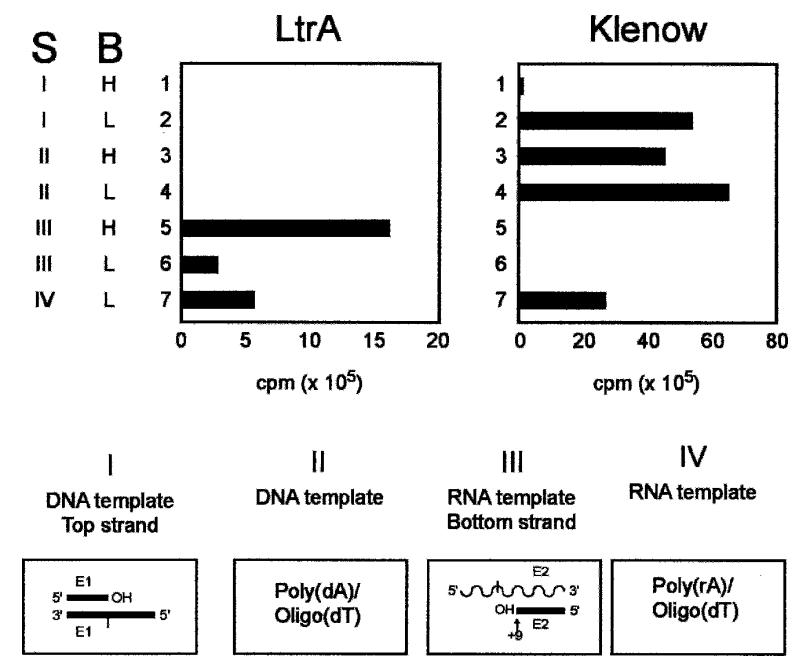

Figure 3. LtrA polymerization activity on RNA and DNA templates. DNA-dependent DNA polymerase and RT assays were done with four different template-primer substrates (S, I-IV; depicted below the graphs). Reactions contained the indicated enzymes and $10 \mu \mathrm{Ci}\left[\alpha{ }^{32} \mathrm{P}\right] \mathrm{dTTP}$ (plus $200 \mu \mathrm{M}$ dATP, dCTP, and dGTP for substrates I and III) in buffers (B) that contained high $(\mathrm{H})$ or low (L) salt $(450$ and $100 \mathrm{mM} \mathrm{NaCl}$, respectively; see Materials and Methods). In other experiments, LtrA showed no detectable activity with substrate I in reaction medium optimal for Klenow or M-MLV RT (REact2 and first-strand buffer, respectively; see Materials and Methods). The activity of LtrA with substrate II remained $<5 \%$ of that with substrate IV in reaction medium containing lower salt $(10 \mathrm{mM} \mathrm{NaCl})$, and the ratio of activities with substrates II and IV remained the same with $10 \mu \mathrm{M}$ unlabeled dTTP added or with different LtrA concentrations $(20,200$, or $2000 \mathrm{nM})$. LtrA also displayed very low processive DNA polymerase activity with substrate I relative to RT activity with substrate III in PAGE assays for extension of $5^{\prime}-{ }^{32} \mathrm{P}$-labeled primer with $200 \mu \mathrm{M}$ of each $\mathrm{dNTP} \mid<2.5 \%$ at 100 $\mathrm{mM} \mathrm{NaCl}$ and 0 at $450 \mathrm{mM} \mathrm{NaCl}$ ) (data not shown). polymerase activity (i.e., incorporation above background) was detected with the top-strand synthesis substrate (I) and only very low activity was detected with poly $(\mathrm{dA}) /(\mathrm{dT})_{18}$ under different conditions, including high-salt (H) or low-salt (L) buffers (assays 1-4), further decreased salt concentrations, higher LtrA and dTTP concentrations, and reaction buffers optimal for Klenow or M-MLV-RT (see Fig. 3 legend). Furthermore, no significant DNA-dependent DNA polymerase activity with substrate I was found for RNPs, consisting of the Ll.LtrB lariat intron RNA and the LtrA protein (data not shown). As a control, Klenow showed high activities in the DNAdependent DNA polymerase assays (assays 2-4), but not in the bottom-strand RT assay (assays 5 and 6). Klenow also displayed substantial activity with poly(rA)/oligo(dT) ${ }_{18}$ (assay 7), likely reflecting its cryptic RT activity (Springgate et al. 1973). Although we cannot exclude a difference between in vitro and in vivo conditions, the finding that LtrA has strong RT activity but little, if any, processive DNA-dependent DNA polymerase activity under a wide range of conditions, suggests that secondstrand DNA synthesis is likely carried out by one or more host DNA polymerases.

\section{A role for the major replicative polymerase in retrohoming}

To determine whether replication of the recipient plasmid contributes to intron retrohoming, we used realtime PCR to assay retrohoming of the intron into the target site carried on a ts plasmid. For the mobility assay, pB102B-ltrB, a ts recipient plasmid, or its wild-type thermoresistant counterpart pB101B-ltrB (Fig. 4A; Supplementary Fig. S1C, cross 6), was transformed into cells containing the intron-donor plasmid pACD2 (Fig. 4A; Supplementary Fig. S1C, cross 5). Transformants were grown in $\mathrm{LB}$ medium at $30^{\circ} \mathrm{C}$, the permissive temperature, or $37^{\circ} \mathrm{C}$, the semirestrictive temperature for replication of the ts plasmid. Plasmid DNAs isolated from transformants grown for various times were subjected to real-time PCR to quantify intron homing. As shown in Figure $4 \mathrm{~A}$, intron integration into the ts recipient plasmid increased steadily at $30^{\circ} \mathrm{C}$, but not at $37^{\circ} \mathrm{C}$, while intron integration into the wild-type recipient plasmid increased at both temperatures. Although the reason for the fluctuation in homing frequencies at $37^{\circ} \mathrm{C}$ is not understood, the reduced mobility levels when the ts replicon is inhibited are reproducible, indicating that DNA replication is required for intron retrohoming.

We therefore wished to determine whether the major E. coli polymerases I ( $\mathrm{Pol}$ I) and/or III (Pol III) are required for retrohoming. We first tested Pol I, the DNA polymerase that acts in lagging strand DNA synthesis and DNA excision repair, and found that loss of the polymerase and associated $3{ }^{\prime}-5$ ' exonuclease activities do not significantly affect retrohoming (Table 3).

Pol III, the major replicative polymerase in E. coli, is essential for cell viability; accordingly, only ts mutants are available. Using a dnaE Pol III mutant, which is defective in the $\alpha$-subunit of the Pol III core enzyme (Fig. 
Smith et al.

Figure 4. DNA replication and retrohoming. (A) Real-time PCR assay for replication dependence of retrohoming. Cells containing intron-donor plasmid pACD2 and a ts recipient plasmid pB102B-ltrB, or the corresponding wild-type recipient plasmid pB101B-ltrB, were grown either at the permissive temperature $\left(30^{\circ} \mathrm{C}\right)$ or the semirestrictive temperature $\left(37^{\circ} \mathrm{C}\right)$. Plasmid DNAs were isolated at the indicated times and were used as the template in two independent real-time PCR reactions to quantify homing products and recipient plasmids. The relative mobility frequency was calculated as the ratio of homing product/(homing product + recipient). (B) Intron homing in a Pol III mutant. Cross 3 (shown in Fig. 2A,B) was performed in $\mathrm{AB} 1157$ (denoted wild type) and $\mathrm{AB} 1157 \mathrm{dnaE}$ at $30^{\circ} \mathrm{C}, 37^{\circ} \mathrm{C}$, and $42^{\circ} \mathrm{C}$. Mobility frequency was determined for three independent experiments and is expressed as the percentage of homing products per recipient.
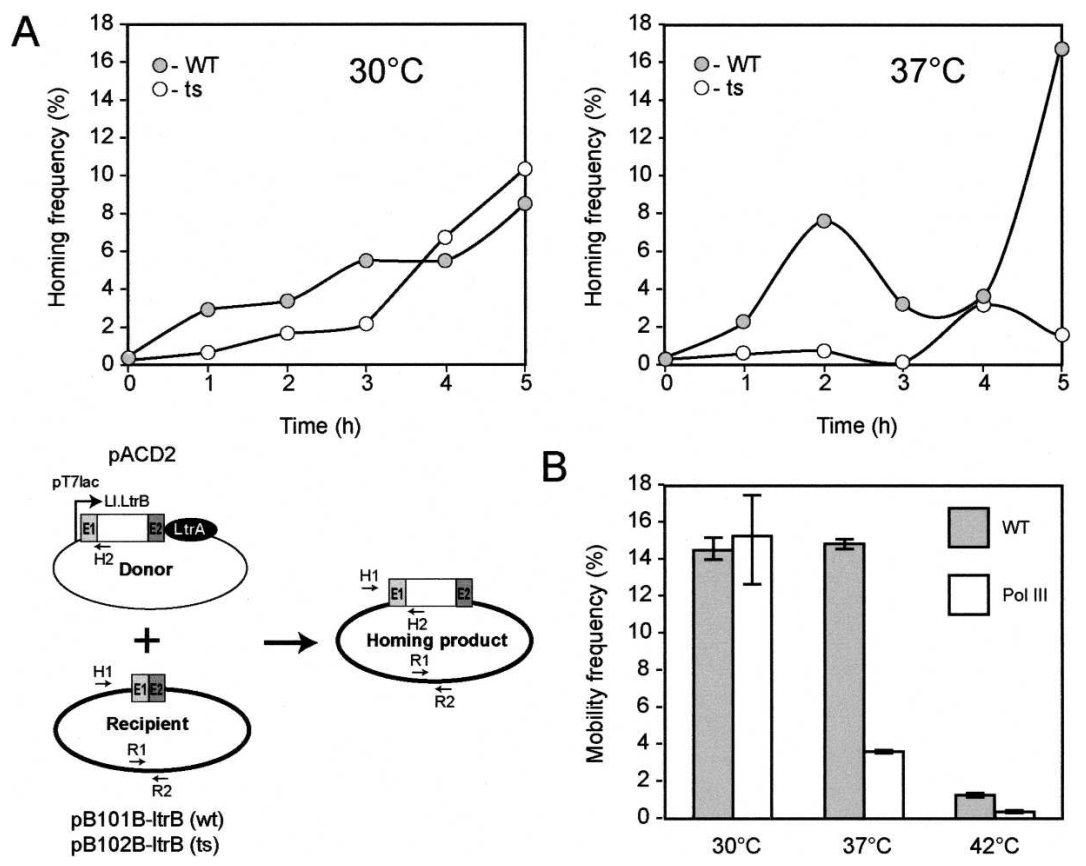

B

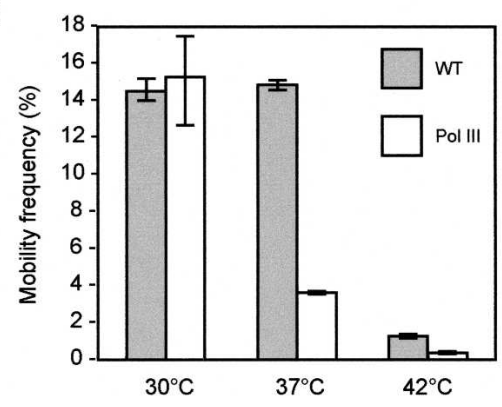

$2 \mathrm{~B}$, cross 3 ), we showed that intron mobility was the same as that in the wild type at the permissive temperature of $30^{\circ} \mathrm{C}$ (Fig. 4B). However, retrohoming decreased approximately fourfold at the restrictive temperature of $37^{\circ} \mathrm{C}$ and decreased approximately fivefold at $42^{\circ} \mathrm{C}$ (Fig. $4 \mathrm{~B}$; Table 3 ). At $42^{\circ} \mathrm{C}$, intron mobility in the wild-type strain also decreased, $\sim 10$-fold from that at $30^{\circ} \mathrm{C}$ or $37^{\circ} \mathrm{C}$, reflecting a general inhibitory effect on viability and homing when cells are grown at high temperature. For this reason, the $37^{\circ} \mathrm{C}$ numbers are reported in Table 3. The residual mobility in the dnaE mutant at $37^{\circ} \mathrm{C}$ and $42^{\circ} \mathrm{C}$ could result from the occurrence of retrohoming before the temperature shift, owing to leaky expression of the intron, from the involvement of other cellular polymerases, or from residual Pol III activity at elevated temperatures. Together, the data likely reflect not only the dependency of intron homing on DNA replication (Fig. 4A), but also the reliance of group II intron mobility on Pol III for second-strand cDNA synthesis.

\section{DNA repair polymerases contribute to retrohoming}

A possible role for the three SOS-inducible polymerases Pol II, Pol IV, and Pol V was also probed, because retrohoming may require activities similar to those that are recruited to repair damaged DNA. Pol II, the product of

Table 3. Retrohoming in replicative and repair polymerase mutants

\begin{tabular}{|c|c|c|}
\hline Mutant (mutation) ${ }^{\mathrm{a}}$ & Function & Homing efficiency ${ }^{\mathrm{b}}$ \\
\hline \multicolumn{3}{|l|}{ Major polymerases } \\
\hline Pol I-5'-3' exo (polA107Tn10::kan) & Lacks 5'-3' exonuclease (DNase and RNase) & $0.24 \pm 0.11$ \\
\hline 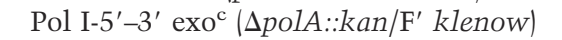 & & $<3.6 \times 10^{-3 \mathrm{~d}}$ \\
\hline Pol I-klenow 3'-5' exo (polA1[am]Tn10) & Lacks Klenow including polymerase and $3^{\prime}-5^{\prime}$ exonuclease & $0.73 \pm 0.34$ \\
\hline Pol III $\mathrm{e}^{\mathrm{e}}($ dnaE486[ts]) & Major replicative enzyme $\left[37^{\circ} \mathrm{C}\right]$ & $\begin{array}{l}0.32 \pm 0.14^{\mathrm{e}} \\
0.24 \pm 0.01^{\mathrm{e}}\end{array}$ \\
\hline \multicolumn{3}{|l|}{ Repair Polymerases } \\
\hline Pol II (spolB::spc) & Error-free restart & $0.32 \pm 0.10$ \\
\hline Pol IV ( $\Delta$ dinB::kan) & Extends stalled fork & $0.37 \pm 0.14$ \\
\hline Pol V (sumuDC596) & Mutagenic translesion synthesis & $1.49 \pm 0.34$ \\
\hline Pol II/IV & - & $0.30 \pm 0.18$ \\
\hline Pol II/V & - & $0.08 \pm 0.03$ \\
\hline Pol IV/V & - & $0.11 \pm 0.03$ \\
\hline $\mathrm{Pol} \mathrm{II} / \mathrm{IV} / \mathrm{V}$ & - & $0.08 \pm 0.02$ \\
\hline
\end{tabular}

${ }^{\mathrm{a}, \mathrm{b}}$ As footnotes a and b of Table 1 .

${ }^{\mathrm{c}}$ This strain lacks the activity shown in the Mutant column. The wild-type parent to which the homing efficiencies were normalized is $\Delta$ polA::kan $/ F^{\prime}$ polA (Joyce and Grindley 1984).

${ }^{\mathrm{d}}$ Although replication was 10 -fold depressed, the effect was neglible relative to $>300$-fold decrease in homing efficiency.

'See also Figure 4. Upper and lower numbers correspond to crosses 1 and 3, respectively. 
the $p o l B$ gene, is a restart polymerase, which, in concert with a Pol III complex and a restart primosome complex, catalyzes error-free replication-restart (for review, see Goodman 2000; Sutton and Walker 2001). In contrast, Pol IV $(\operatorname{din} B)$ copies undamaged DNA at stalled replication forks, which arise in the cell from mismatched or misaligned primer ends. Although Pol IV exhibits low processivity (6-8 nt before dissociation), association with Pol III causes a 3000-fold increase in DNA synthesis efficiency (Tang et al. 2000). Finally, Pol V, a product of the umuDC complex, is also nonprocessive, but is engaged in error-prone translesion synthesis (Sutton and Walker 2001).

Whereas Pol II and Pol IV single mutants were reduced threefold, the Pol V mutant was approximately 1.5-fold stimulated. The Pol II-Pol IV double mutant again yielded a threefold drop in retrohoming, whereas defects in Pol V together with Pol II or Pol IV mutations gave more dramatic results; the Pol II-Pol V, Pol IV-Pol V, and Pol II-Pol IV-Pol V mutants were 10-fold reduced in their ability to sustain retrohoming. Thus, in addition to a role identified for the replicative Pol III polymerase, the repair polymerases appear to have a substantial collective effect on retrohoming.

\section{Discussion}

By taking advantage of the well-characterized genetic background and biochemical machinery of E. coli, we show that group II intron retrohoming is dependent on host DNA- and RNA-processing functions, and obtain for the first time, a view of non-LTR retroelement function in a cellular context. We screened a battery of $>30 \mathrm{E}$. coli mutants and identified several with strong (greater than or equal to threefold) and reproducible stimulatory or inhibitory effects on retrohoming. Stimulatory functions were RecJ, MutD, and SbcD nucleases, components of all five of the E. coli DNA polymerases, RNase $\mathrm{H}$, and DNA ligase, whereas inhibitory functions were RNases I and E and Exo III. These accessory functions have been placed in the framework of the retrohoming pathway (Figs. 1, 5). While our results do not eliminate the possibility that some host accessories have been overlooked and that interpretations may be complicated by multiple functions of the proteins or indirect effects, a clear pattern has emerged. The theme is that after the initial steps of retrohoming, the group II intron recruits multiple host functions and becomes subsumed into cellular replication and repair pathways.

\section{A balance of inhibitory and stimulatory host functions in the initial steps of retrohoming}

The first steps of reverse-splicing into the recipient DNA, second-strand DNA cleavage, and TPRT (Figs. 1, 5 , steps 1-3) can occur in vitro and require only the catalytic activities of the intron RNA and the LtrA protein (Saldanha et al. 1999). These steps appear sensitive to host ribonucleases I and E (Table 2), probably due to in-

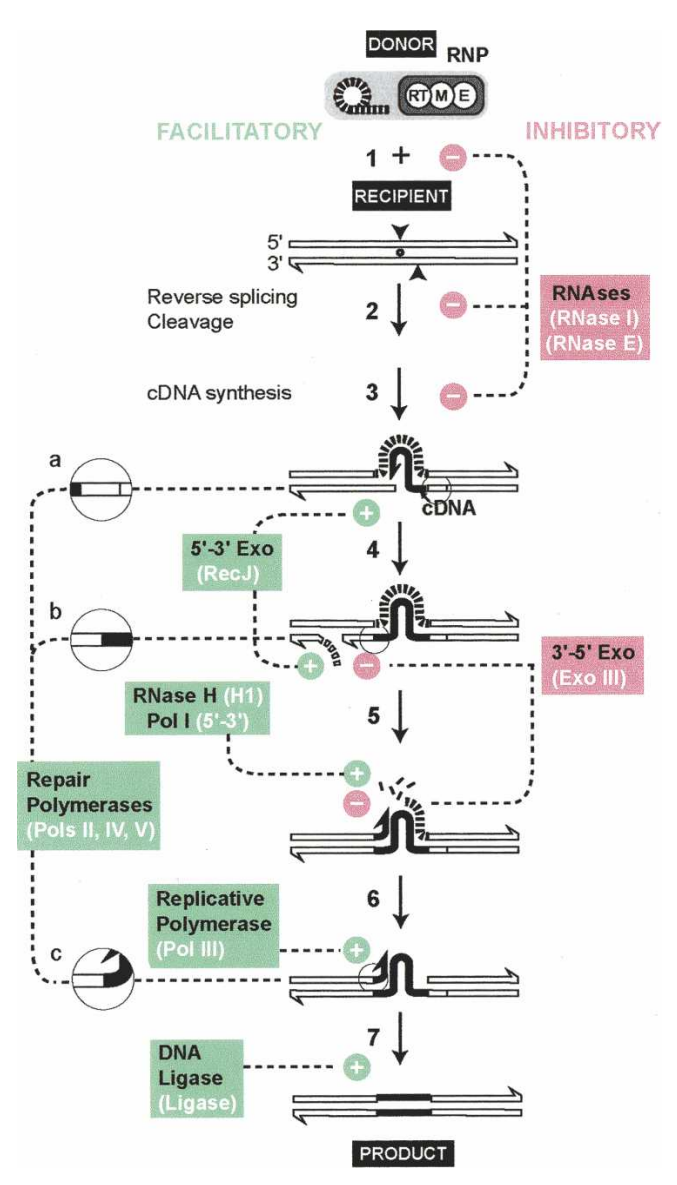

Figure 5. Roles of accessory functions in retrohoming. Facilitatory $(+$, teal) and inhibitory $(-$, red) functions are superimposed on a retrohoming pathway that is expanded from that in Figure 1. The order of steps 5 and 6 is arbitrary. Accessory functions are labeled in black on a teal or red background, with implicated $E$. coli enzymes in white. Their putative sites of action are indicated by dotted lines, as described in the text. Three possible sites of DNA synthesis by the repair polymerases are encircled and enlarged on the left $(\mathrm{a}-\mathrm{c})$.

tron degradation before reverse splicing or cDNA synthesis (Fig. 5, steps 1-3).

Deoxyribonucleases are suspected of playing major, albeit hypothetical, roles in subsequent steps. Following synthesis of a full-length intron cDNA, 5' $-3^{\prime}$ resection or unwinding of the $5^{\prime}$ exon DNA may be required to allow the nascent cDNA to pair with the top strand (Fig. 5, step 4). RecJ deletion causes a fivefold reduction in retrohoming (Table 1), and could be a 5'-3' exonuclease involved in this step. Interestingly, among the five DNA helicases tested, only RecQ, which collaborates with RecJ to process stalled replication forks (Courcelle et al. 2003), has any facilitatory effect, albeit small.

Another exonuclease to be considered, with an almost fourfold effect on retrohoming, is MutD (DnaQ), a $3^{\prime}-5^{\prime}$ exonuclease. MutD is a subunit $(\varepsilon)$ of Pol III holoenzyme, and carries out proofreading in the E. coli replication complex (Fersht and Knill-Jones 1983). Given that processive DNA synthesis is contingent upon this exo- 
nuclease subunit of the Pol III holoenzyme (Studwell and O'Donnell 1990), the phenotype of the MutD mutant fits well with the role of Pol III in second-strand cDNA synthesis (Figs. 4, 5, step 6). It is also possible that a $3^{\prime}-5^{\prime}$ exonuclease activity is required after removal of RNA, to cut back into the $5^{\prime}$ exon, prior to second-strand synthesis by Pol III.

Retrohoming is reduced about fourfold in an SbcD mutant (Table 1). The SbcCD nuclease is involved in the structural maintenance of chromosomes, by cleaving DNA hairpins and other secondary structures that inhibit DNA replication (Connelly et al. 1998). Since the replication machinery is intimately involved in retrohoming, and stalled forks may well be intermediates in this process, we speculate that the role of SbcCD nuclease is in cleavage of inhibitory secondary structures at such forks.

Mutation of $x t h A$, which encodes Exo III, elevates retrohoming by more than eightfold. This characteristic may result from Exo III's 3'-5' exonuclease activity degrading the newly synthesized cDNA, restoring the gap, and thereby inhibiting the repair process (Fig. 5, step 5). Alternatively, Exo III may degrade the top strand in the upstream exon and/or compete with Pol III for primers of second-strand synthesis (Fig. 5, step 6). Together, these results indicate that a delicate balance of inhibitory and facilitatory activities combine to effect, and possibly to regulate, retrohoming; then DNA ligase, with a fourfold effect in a ts mutant (Table 1), likely completes the process by sealing nicks left in the DNA (Fig. 5, step 7).

RNase H, Pol I, and the removal of intron RNA after reverse transcription

After reverse transcription, the intron RNA must be removed for synthesis of the second-strand using the cDNA as template (Fig. 5, step 5). Unlike retroviruses and LTR-retrotransposons, group II introns and nonLTR-retrotransposons do not encode their own RNases $\mathrm{H}$ (Malik and Eickbush 2001). We have shown here that of the two E. coli RNases H, RNase $\mathrm{H} 1$ plays an important role in retrohoming (Table 2; see also Supplementary Table S2), suggesting that group II introns can use a host $\mathrm{RNase} \mathrm{H}$ to remove the RNA template after reverse transcription.

Two different Pol I mutants that lack the $5^{\prime}-3^{\prime}$ exonuclease activity, which may also act to remove the intron RNA template after reverse transcription, are strongly depressed in mobility. Whereas the $r n h A$ gene, which encodes RNase $\mathrm{H} 1$, can complement an RNase H1 defect (Table 2), it fails to complement a Pol I 5'-3' defect, suggesting that the putative role of Pol I in RNA degradation is distinct from that of RNase H1. Indeed, whereas RNase $\mathrm{H}$ endonucleolytically cleaves the RNA strand in an RNA/DNA hybrid, Pol I is a 5'-3' exonuclease (Kornberg and Baker 1992). Furthermore, since Pol I $5{ }^{\prime}-3^{\prime}$ exo and Pol III act in concert at replication forks (Lopez de Saro and O'Donnell 2001) and since our data support Pol III being responsible for second-strand syn- thesis, a role for Pol I 5'-3' exonuclease in the removal of RNA seems likely.

\section{Pol III and second-strand DNA synthesis}

Although the RTs of retroviruses and LTR retrotransposons have DNA-dependent DNA polymerase activity, this has not previously been tested quantitatively for members of the non-LTR retrotransposon superfamily, including group II introns. Although LtrA can copy the 5' overhang of the 3' exon DNA during initiation of TPRT (Saldanha et al. 1999), it has very low processive DNAdependent polymerization activity on other substrates in vitro (Fig. 3), suggesting that second-strand synthesis may be carried out by a host polymerase.

The candidate functions are the two major polymerases in E. coli, Pol I and Pol III. Athough retrohoming was unaffected in a Pol I mutant lacking polymerization and $3{ }^{\prime}-5$ ' exonuclease activities, Pol III was implicated (Table 3; Fig. 4B). A ts mutation in the catalytic $\alpha$ subunit of Pol III, the 10-subunit processive host polymerase, resulted in a sharp, temperature-dependent reduction in intron mobility (Fig. 4B). This result, along with the need for MutD, the $\varepsilon$ subunit of Pol III (Table 1), makes the major replicative enzyme of E. coli a primary candidate for second-strand cDNA synthesis in retrohoming (Fig. 5, step 6). The involvement of Pol III could explain the requirement for active DNA replication suggested by the real-time PCR experiment. This proposal is consistent with other results that imply a strong link between DNA replication and mobility in E. coli (Zhong et al. 2003; Coros et al. 2005).

\section{Repair polymerases have a role in retrohoming}

Mutations in Pol II and/or Pol IV, when combined with a mutation in Pol V, lead to a 10 -fold reduction in retrohoming (Table 3), suggesting a need for repair polymerization across DNA lesions or DNA-RNA junctions. The physical association of all five polymerases and DNA ligase, through their interaction via the $\beta$ clamp, provides a molecular framework for the collaboration of these different enzymes (Lopez de Saro and O'Donnell 2001; Lopez de Saro et al. 2003; Plosky and Woodgate 2004).

Pol II, Pol IV, and Pol V provide a pool of accessory DNA polymerases with relaxed specificity, which assist the high-fidelity processive Pol III (Wagner et al. 2002). In various combinations, and with a great deal of functional redundancy, Pol II, Pol IV, and Pol V help bypass lesions when Pol III dissociates from a damaged primer-template (for review, see Plosky and Woodgate 2004; Tippin et al. 2004). Which of the three repair polymerases replaces the displaced Pol III in a complex depends on timing, enzyme availability, and the type of DNA lesion (Crowley and Courcelle 2002; Goodman 2002; Wagner et al. 2002). Our results indicate that in the Pol V mutant, retrohoming increases by $50 \%$ (Table 3 ), which may be consistent with the observation that Pol III can replicate efficiently 
past some DNA lesions when Pol V is inactivated (Borden et al. 2002). Although the lack of Pol II or Pol IV can reduce retrohoming by two-thirds, the Pol II-Pol IV double mutant does not have an additive effect. These results suggest that Pol II and Pol IV function similarly in retrohoming. However, in combination with a Pol V mutant, the Pol II and Pol IV mutants have 10-fold effects, underscoring the complex interdependencies of these enzymes (Sutton and Walker 2001). This functional enhancement by Pol V may be related to the finding that Pol II mutants are not sensitive to UV light, and Pol V mutants are only slightly sensitive, whereas Pol II-Pol V double mutants are extremely UV-sensitive (Goodman 2002).

There are at least three points in the retrohoming pathway at which repair polymerases might function. First, although LtrA can copy the 5' overhang of $3^{\prime}$ exon DNA in vitro, given its low DNA polymerase activity, it is conceivable that repair polymerases contribute to this step in vivo (Fig. 5, intermediate a). Second, repair polymerases may be required to traverse the RNA-DNA junction of the template at the $5^{\prime}$ splice site to continue DNA synthesis into the $5^{\prime}$ exon (Fig. 5, intermediate b). Third, the repair polymerases may be needed to initiate second-strand synthesis (Fig. 5, intermediate c). If there is residual RNA attached to the top strand of the upstream exon, then the accommodating active site of a repair polymerase (Kunkel 2004) may more readily initiate second-strand synthesis than Pol III.

Although RecA is required for induction of SOS-dependent repair functions, constitutive levels of the repair polymerases Pol II and Pol IV are fairly high (Goodman 2002), explaining how retrohoming can still occur efficiently in a $\operatorname{rec} A$ background. It remains puzzling, however, that we have not observed a high frequency of errors, even at the junctions of retrohoming events (D. Smith and M. Belfort, unpubl.). One possibility is that Pol II, which has an error-free pathway (Goodman 2000), is the major repair polymerase involved. A second possibility is that MutD, which is part of the Pol III holoenzyme, and which may play a role in retrohoming (Table 1), is involved in error correction. Regardless, the dependency of group II intron mobility on the repair polymerases suggests that the later steps of the retrohoming process may be viewed as a response to DNA damage.

\section{Retroelements as molecular parasites that scavenge host functions}

Group II introns are streamlined parasitic elements, carrying only those molecular features that are required to maintain themselves in a genome and to spread to others. Some bacterial group II IEPs, for example, lack the endonuclease module (Martínez-Abarca et al. 2000; Dai and Zimmerly 2002), and these introns may achieve mobility by utilizing a cellular replication pathway (Martinez-Abarca et al. 2004). Together with the recruitment of host replication and repair functions demonstrated here, it appears that group II introns scavenge much of their enzymatic machinery from the hosts they invade.

Features of the mechanism used by group II introns may be pertinent to non-LTR-retrotransposons, such as human LINE elements and insect R2 elements, and more generally to other non-LTR-retroelements, including retroplasmids and bacterial retrons. The replicative and repair polymerases have homologs not only in other bacteria, including Gram-positives from which the Ll.LtrB intron was derived, but also in phylogentically diverse eukaryotes (Crowley and Courcelle 2002; Goodman 2002; Plosky and Woodgate 2004; Tippin et al. 2004). It is therefore possible that replicative polymerases in a wide range of organisms are involved in second-strand synthesis, with specific steps aided by repair polymerases, or even that second-strand synthesis could occur during the normal course of DNA replication. To our knowledge, no evidence exists to the contrary. What these elements almost certainly have in common with group II introns is that they encode enzymes that promote initial steps in mobility, whereas later steps use host DNA recombination and repair machinery, thereby facilitating the element's dispersal.

\section{Materials and methods}

\section{Bacterial strains and plasmids}

Strains used in this study, made lysogenic for $\lambda \mathrm{DE} 3$, are listed in Supplementary Table S4. Plasmids used as intron donors and recipients are listed in Figure 2B, with salient features, including drug resistances and origins of replication. Additionally, the length of the intron donor is noted. More details on these plasmids and their construction are in the Supplemental Material. The ts recipient plasmid pB102B-ltrB, which was used in real-time PCR experiments (Fig. 4A), was constructed similarly to pB101B-ltrB (Zhong and Lambowitz 2003), except that the ts replicon was amplified from pMAK705 (Hamilton et al. 1989).

\section{Retrohoming assay}

The retrohoming assay was performed as described (Cousineau et al. 1998) and is detailed in the Supplemental Material. Briefly, donor and recipient plasmids were cotransformed into the $E$. coli strain being tested (Fig. 2). Fresh cotransformants were grown overnight in TBYE ( $1 \%$ Bactone tryptone, $0.5 \% \mathrm{NaCl}$, $0.1 \%$ Bacto yeast extract) with antibiotics corresponding to intron and plasmid markers IM, PM1, and PM2. After outgrowth and induction of the donor intron with IPTG for $3 \mathrm{~h}$, plasmid DNA was extracted, digested with the appropriate restriction enzymes, transformed into DH5 $\alpha$ cells, and selected for IM and PM2.

\section{Biochemical assays}

DNA polymerase and RT assays were carried out with the primer-template substrates (S, I-IV) shown in Figure 3. Substrate I was made with $40 \mathrm{nM}$ DNA oligonucleotide LtrBAs6 (see Supplementary Table S5 for the sequences of oligonucleotides), corresponding to bottom-strand 5 '-exon nucleotides -18 to 72 of the Ll.LtrB intron, and $400 \mathrm{nM}$ oligonucleotide LtrBDE3, corresponding to top strand 5'-exon nucleotides -18 
to -1 . Substrate III, denoted L1.LtrB/E2+10, was made with 40 nM PAGE-purified Ll.LtrB- $\Delta$ ORF intron precursor RNA and 400 nM 18-mer DNA oligonucleotide, ending at bottom-strand 3' exon nucleotide +10 (Wank et al. 1999). Substrates II and IV were $1 \mu \mathrm{g}$ of poly $(\mathrm{dA}) /$ oligo $(\mathrm{dT})_{12-18}$ or $\operatorname{poly}(\mathrm{rA}) / \mathrm{oligo}(\mathrm{dT})_{12-18}$ respectively, prepared as described (Matsuura et al. 1997).

Unless specified otherwise, reactions were for $10 \mathrm{~min}$ at $37^{\circ} \mathrm{C}$ in $10 \mu \mathrm{L}$ of reaction mix containing $10 \mu \mathrm{Ci}\left[\alpha{ }^{32} \mathrm{P}\right] \mathrm{dTTP}(3000$ $\mathrm{Ci} / \mathrm{mmol}$; NEN-Dupont) with $200 \mu \mathrm{M}$ dATP, dCTP, and dGTP added for substrates I and III. Reaction mixes were NMT450 (high salt) (450 mM NaCl, $5 \mathrm{mM} \mathrm{MgCl}_{2}, 40 \mathrm{mM}$ Tris- $\mathrm{HCl}$ at $\mathrm{pH}$ 7.5, $5 \mathrm{mM} \mathrm{DTT}, 100 \mu \mathrm{g} / \mathrm{mL} \mathrm{BSA}$, and $5 \%$ glycerol), which is optimal for LtrA reverse transcription of Ll.LtrB RNA/E2 DNA + 10 (substrate III); NMT100 (low salt) (100 mM NaCl, 5 $\mathrm{mM} \mathrm{MgCl}_{2}, 40 \mathrm{mM}$ Tris- $\mathrm{HCl}$ at $\mathrm{pH}$ 7.5, $5 \mathrm{mM} \mathrm{DTT}, 100 \mu \mathrm{g} / \mathrm{mL}$ BSA, and $5 \%$ glycerol), for use of poly $(\mathrm{rA}) /$ oligo $(\mathrm{dT})_{18}$ (substrate IV) (Wank et al. 1999); REact2 buffer (50 mM Tris-HCl at $\mathrm{pH} 8.0$, $10 \mathrm{mM} \mathrm{MgCl} 2,50 \mathrm{mM} \mathrm{NaCl}$ ), which is optimal for Klenow; or first-strand buffer $(50 \mathrm{mM}$ Tris- $\mathrm{HCl}$ at $\mathrm{pH} 8.3,75 \mathrm{mM} \mathrm{KCl}, 5$ $\mathrm{mM} \mathrm{MgCl}$, and $1 \mathrm{mM} \mathrm{DTT)}$, which is optimal for M-MLV RT (Invitrogen). LtrA (20 nM) or Klenow (1 unit; Invitrogen) were added to the premixed substrates to initiate reactions. After incubation, $9 \mu \mathrm{L}$ of the reaction mixture was spotted on DE81 filter paper, followed by five washes in $2 \times$ SSC. Dried filters were then counted for Cerenkov radioactivity.

Target DNA-primed reverse transcription was assayed using recipient plasmid pLHS, as described (Saldanha et al. 1999).

\section{Intron mobility assay using quantitative real-time PCR}

Recipient plasmid pB102B-ltrB (5 $\mu \mathrm{g})$ was introduced into HMS174(DE3) containing the intron-donor plasmid pACD2 (plasmids described in Supplemental Material). After recovery in $5 \mathrm{~mL}$ of $\mathrm{LB}$ medium for $2 \mathrm{~h}$ at $30^{\circ} \mathrm{C}$, cells were collected by centrifugation, washed with $7 \mathrm{~mL}$ of $\mathrm{LB}$ medium twice to remove the untransformed recipient plasmids, and resuspended in $50 \mathrm{~mL}$ of LB medium. Transformed cells were grown at 30 or $37^{\circ} \mathrm{C}$, and $1.5-\mathrm{mL}$ portions were removed at the indicated times for plasmid isolation. Plasmid DNA $(2 \mu \mathrm{L})$ was used in a quantitative real-time PCR that contains $900 \mathrm{nM}$ primers and 250 nM TaqMan probe (Applied Biosystems) to monitor homing of the intron into the target site. Briefly, primers HP1, HP2 with probe HPP, and primers R1, R2 with probe RP were used to quantify homing products, and the sum of the recipient plasmids and the homing products, respectively (sequence of primers and probes are listed in Supplementary Table S5). Real-time PCR was carried out using a TaqMan Universal PCR kit, and the products were analyzed in an ABI PRISM 7700 sequence detection system. Standard curves for both homing product and recipient plasmid were plotted from PCR of serial dilutions of plasmid pB102B-ltrBHP, which contains the Ll.LtrB- $\Delta$ ORF intron inserted in the target site of pB102B-ltrB. Two duplicate PCRs were performed for each sample and the average threshold cycle $\left(\mathrm{C}_{\mathrm{T}}\right)$ was plotted on the standard curve to determine the relative quantity of initial PCR templates, either the homing products or the sum of the homing products and the recipient plasmids. Mobility frequencies were calculated as the ratio of homing product/(recipient plasmid + homing product).

\section{Acknowledgments}

We thank Dr. Benoit Cousineau for productive discussions during the early stages of this work, and Drs. Cathy Joyce, Susan Lovett, Myron Goodman, and Roger Woodgate for bacterial strains and useful discussions. We also appreciate receiving strains from Drs. Alvin J. Clark, Joe Heitman, Mitsuhiro Itaya, Richard Kolodner, Sidney Kushner, Bob Lloyd, Benedict Michel, and Gerry Smith. We are grateful to Maryellen Carl and John Dansereau for expert manuscript and figure preparation, respectively, and to Drs. Colin Coros, Kenji Ichiyanagi, and Janice Pata for insightful comments on the manuscript. This work was supported by NIH grants GM39422 and GM44844 to M.B. and GM37949 to A.M.L.

\section{References}

Belfort, M., Derbyshire, V., Parker, M.M., Cousineau, B., and Lambowitz, A.M. 2002. Mobile introns: Pathways and proteins. In Mobile DNA II (ed. N.L. Craig et al.), pp. 761-783. ASM Press, Washington, DC.

Borden, A., O'Grady, P.I., Vandewiele, D., Fernández de Henestrosa, A.R., Lawrence, C.W., and Woodgate, R. 2002. Escherichia coli DNA polymerase III can replicate efficiently past a T-T cis-syn cyclobutane dimer if DNA polymerase V and the $3^{\prime}$ to $5^{\prime}$ exonuclease proofreading function encoded by dnaQ are inactivated. J. Bacteriol. 184: 2674-2681.

Brescia, C.C., Kaw, M.K., and Sledjeski, D.D. 2004. The DNA binding protein $\mathrm{H}-\mathrm{NS}$ binds to and alters the stability of RNA in vitro and in vivo. J. Mol. Biol. 339: 505-514.

Connelly, J.C., Kirkham, L.A., and Leach, D.R. 1998. The SbcCD nuclease of Escherichia coli is a structural maintenance of chromosomes (SMC) family protein that cleaves hairpin DNA. Proc. Nat1. Acad. Sci. 95: 7969-7974.

Coros, C.J., Landthaler, M., Piazza, C.L., Beauregard, A., Esposito, D., Perutka, J., Lambowitz, A.M., and Belfort, M. 2005. Retrotransposition strategies of the Lactococcus lactis Ll.LtrB group II intron are dictated by host identity and cellular environment. Mol. Microbiol. 56: 509-524.

Courcelle, J., Donaldson, J.R., Chow, K.H., and Courcelle, C.T. 2003. DNA damage-induced replication fork regression and processing in Escherichia coli. Science 299: 1064-1067.

Cousineau, B., Smith, D., Lawrence-Cavanagh, S., Mueller, J.E., Yang, J., Mills, D., Manias, D., Dunny, G., Lambowitz, A.M., and Belfort, M. 1998. Retrohoming of a bacterial group II intron: Mobility via complete reverse splicing, independent of homologous DNA recombination. Cell 94: 451-462.

Crowley, D.J. and Courcelle, J. 2002. Answering the call: Coping with DNA damage at the most inopportune time. J. Biomed. Biotech. 2: 66-74.

Cusick, M.E. and Belfort, M. 1998. Domain structure and RNA annealing activity of Escherichia coli regulatory protein StpA. Mol. Microbiol. 28: 847-857.

Dai, L. and Zimmerly, S. 2002. Compilation and analysis of group II intron insertions in bacterial genomes: Evidence for retroelement behavior. Nucleic Acids Res. 30: 1091-1102.

Eickbush, T.H. 2002. R2 and related site-specific non-long terminal repeat retrotransposons. In Mobile DNA II (ed. N.L. Craig, R. Craigie, M. Gellert, and A.M. Lambowitz), pp. 813835. ASM Press, Washington, DC.

Eskes, R., Yang, J., Lambowitz, A.M., and Perlman, P.S. 1997. Mobility of yeast mitochondrial group II introns: Engineering a new site specificity and retrohoming via full reverse splicing. Cell 88: 865-874.

Fersht, A.R. and Knill-Jones, J.W. 1983. Contribution of 3'-5' exonuclease activity of DNA polymerase III holoenzyme from Escherichia coli to specificity. J. Mol. Biol. 165: 669682.

Goodman, M.F. 2000. Coping with replication 'train wrecks' in Escherichi coli using Pol V, Pol II and RecA proteins. Trends Biochem. Sci. 25: 189-195. 
2002. Error-prone repair DNA polymerases in prokaryotes and eukaryotes. Annu. Rev. Biochem. 71: 17-50.

Guo, H., Karberg, M., Long, M., Jones III, J.P., Sullenger, B., and Lambowitz, A.M. 2000. Group II introns designed to insert into therapeutically-relevant DNA target sites in human cells. Science 289: 452-457.

Hamilton, C.M., Aldea, M., Washburn, B.K., Babitzke, P., and Kushner, S.R. 1989. New method for generating deletions and gene replacements in Escherichia coli. J. Bacteriol. 171: 4617-4622.

Joyce, C.M. and Grindley, N.D. 1984. Method for determining whether a gene of Escherichia coli is essential: Application to the polA gene. J. Bacteriol. 158: 636-643.

Kornberg, A. and Baker, T.A. 1992. DNA replication. W.H. Freeman and Company, New York.

Kunkel, T.A. 2004. DNA replication fidelity. J. Biol. Chem. 275: 16895-16898.

Lambowitz, A.M. and Zimmerly, S. 2004. Mobile group II introns. Annu. Rev. Genet. 38: 1-35.

Lambowitz, A.M., Mohr, G., and Zimmerly, S. 2005. Group II intron homing endonucleases: Ribonucleoprotein complexes with programmable target specificity. In Homing endonucleases and inteins (eds. M. Belfort et al.), pp. 121-145. Springer-Verlag, Heidelberg, Germany.

Lopez de Saro, F.J.L. and O'Donnell, M. 2001. Interaction of the $\beta$ sliding clamp with MutS, ligase, and DNA polymerase I. Proc. Natl. Acad. Sci. 98: 8376-8380.

Lopez de Saro, F.J., Georgescu, R.E., Goodman, M.F., and O'Donnell, M. 2003. Competitive processivity-clamp usage by DNA polymerases during DNA replication and repair. EMBO J. 22: 6408-6418.

Luan, D.D., Korman, M.H., Jakubczak, J.L., and Eickbush, T.H. 1993. Reverse transcription of R2Bm RNA is primed by a nick at the chromosomal target site: A mechanism for nonLTR retrotransposition. Cell 72: 595-605.

Malik, H.S. and Eickbush, T.H. 2001. Phylogenetic analysis of ribonuclease $\mathrm{H}$ domains suggest a late, chimeric origin of LTR retrotransposable elements and retroviruses. Genome Res. 11: 1187-1197.

Martínez-Abarca, F. and Toro, N. 2000. RecA-independent ectopic transposition in vivo of a bacterial group II intron. Nucleic Acids Res. 28: 4397-4402.

Martínez-Abarca, F., Garcia-Rodriguez, F.M., and Toro, N. 2000. Homing of a bacterial group II intron with an intronencoded protein lacking a recognizable endonuclease domain. Mol. Microbiol. 35: 1405-1412.

Martíinez-Abarca, F., Barrientos-Duran, A., Fernandez-Lopez, M., and Toro, N. 2004. The RmInt1 group II intron has two different retrohoming pathways for mobility using predominantly the nascent lagging strand at DNA replication forks for priming. Nucleic Acids Res. 32: 2880-2888.

Matsuura, M., Saldanha, R., Ma, H., Wank, H., Yang, J., Mohr, G., Cavanagh, S., Dunny, G.M., Belfort, M., and Lambowitz, A.M. 1997. A bacterial group II intron encoding reverse transcriptase, maturase, and DNA endonuclease activities: Biochemical demonstration of maturase activity and insertion of new genetic information within the intron. Genes \& Dev. 11: 2910-2924.

Mills, D.A., McKay, L.L., and Dunny, G.M. 1996. Splicing of a group II intron involved in the conjugative transfer of pRS01 in lactococci. J. Bacteriol. 178: 3531-3538.

Mills, D.A., Manias, D.A., McKay, L.L., and Dunny, G.M. 1997. Homing of a group II intron from Lactococcus lactis subsp. lactis ML3. J. Bacteriol. 179: 6107-6111.

Moran, J.V. and Gilbert, N. 2002. Mammalian LINE-1 retro- transposons and related elements. In Mobile DNA II (eds. N.L. Craig et al.), pp. 836-869. ASM Press, Washington, DC. Nicholson, A.W. 1999. Function, mechanism and regulation of bacterial ribonucleases. FEMS Microbiol. Rev. 23: 371-390.

Plosky, B.S. and Woodgate, R. 2004. Switching from high-fidelity replicases to low-fidelity lesion-bypass polymerases. Curr. Opin. Genet. Dev. 14: 113-119.

Saldanha, R., Chen, B., Wank, H., Matsuura, M., Edwards, J., and Lambowitz, A.M. 1999. RNA and protein catalysis in group II intron splicing and mobility reactions using purified components. Biochemistry 38: 9069-9083.

Shearman, C., Godon, J.-J., and Gasson, M. 1996. Splicing of a group II intron in a functional transfer gene of Lactococcus lactis. Mol. Microbiol. 21: 45-53.

Springgate, C.F., Battula, N., and Loeb, L.A. 1973. Infidelity of DNA synthesis by reverse transcriptase. Biochem. Biophys. Res. Commun. 52: 401-406.

Studwell, P.S. and O'Donnell, M. 1990. Processive replication is contingent on the exonuclease subunit of DNA polymerase III holoenzyme. J. Biol. Chem. 265: 1171-1178.

Sutton, M.D. and Walker, G.C. 2001. Managing DNA polymerases: Coordinating DNA replication, DNA repair, and DNA recombination. Proc. Natl. Acad. Sci. 98: 8342-8349.

Tang, M., Pham, P., Shen, X., Taylor, J.-S., O'Donnell, M., Woodgate, R., and Goodman, M.F. 2000. Roles of E. coli DNA polymerases IV and V in lesion-targeted and untargeted SOS mutagenesis. Nature 404: 1014-1018.

Tippin, B., Pham, P., and Goodman, M.F. 2004. Error-prone replication for better or worse. Trends Microbiol. 12: 288-295.

Wagner, E.G.H., Altuvia, S., and Romby, P. 2002. Antisense RNAs in bacteria and their genetic elements. Adv. Genet. 46: 361-398.

Wank, H., SanFilippo, J., Singh, R.N., Matsuura, M., and Lambowitz, A.M. 1999. A reverse-transcriptase/maturase promotes splicing by binding at its own coding segment in a group II intron RNA. Mol. Cell 4: 239-250.

Zhong, J. and Lambowitz, A.M. 2003. Group II intron mobility using nascent strands at DNA replication forks to prime reverse transcription. EMBO J. 22: 4555-4565.

Zhong, J., Karberg, M., and Lambowitz, A.M. 2003. Targeted and random bacterial gene disruption using a group II intron (targetron) vector containing a retrotransposition-activated selectable marker. Nucleic Acids Res. 31: 1656-1664. 


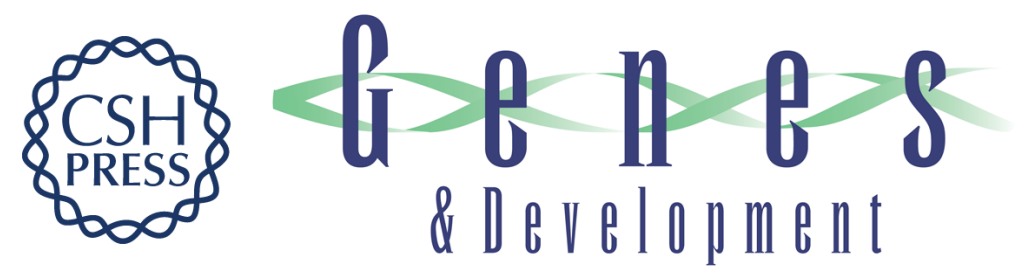

\section{Recruitment of host functions suggests a repair pathway for late steps in group II intron retrohoming}

Dorie Smith, Jin Zhong, Manabu Matsuura, et al.

Genes Dev. 2005, 19:

Access the most recent version at doi:10.1101/gad.1345105

Supplemental http://genesdev.cshlp.org/content/suppl/2005/09/29/19.20.2477.DC1
Material

References This article cites 39 articles, 15 of which can be accessed free at:

http://genesdev.cshlp.org/content/19/20/2477.full.html\#ref-list-1

License

Email Alerting

Receive free email alerts when new articles cite this article - sign up in the box at the top

Service

right corner of the article or click here.

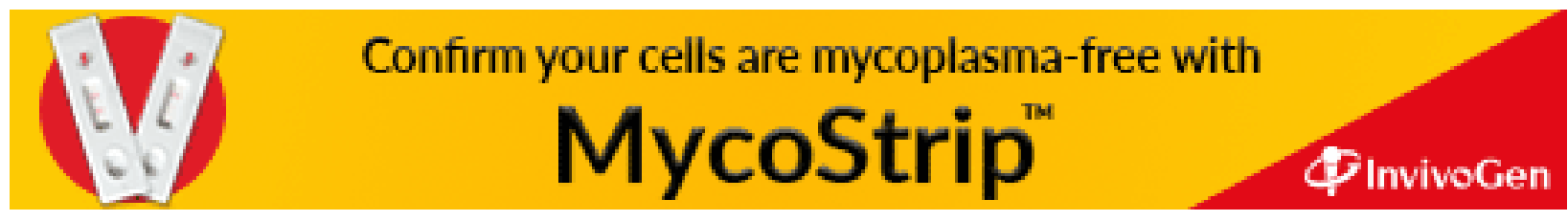

